\title{
O QUE ELES PENSAM SOBRE ELAS? REPRESENTAÇÕES SOCIAIS DA MULHER EXECUTIVA
}

WHAT DO THEY THINK ABOUT THEM? SOCIAL REPRESENTATIONS OF EXECUTIVE WOMEN ¿QUÉ ELLOS PIENSAN SOBRE ELLAS? REPRESENTACIONES SOCIALES DE LA MUJER EJECUTIVA

CAMILA VELOSO ANTUNES

Mestranda

PUC Minas - Brasil

camila.veloso.antunes@gmail.com ORCID: http://orcid.org/0000-0002-8398-9701

ANTONIO CARVALHO NETO

Doutor

PUC Minas- Brasil

carvalhoneto@pucminas.br ORCID: http://orcid.org/0000-0001-5439-2845

ÉRICA CRISTINA PEREIRA LIMA-SOUZA

Mestranda

PUC Minas - Brasil

ericacrislima@yahoo.com.br

ORCID: http://orcid.org/0000-0002-7807-7193

CAROLINA MARIA MOTA SANTOS

Doutora

PUC Minas - Brasil

cmmotasantos@gmail.com

ORCID: http://orcid.org/0000-0001-8830-8170

Submetido em: 26/11/2018

Aprovado em: 28/01/2019

Doi: alcance.v25n3(Set/Dez).p349-365

\section{RESUMO}

O objetivo deste artigo é identificar, a partir da perspectiva dos homens executivos, as representações sociais sobre a mulher executiva quanto à sua atuação no ambiente de trabalho. A metodologia tem abordagem qualitativa; quanto aos objetivos, é descritiva; e o método adotado foi o estudo de casos múltiplos. Foram analisadas três empresas de grande porte do Brasil. A amostra foi composta por 31 executivos com posições de alto nível estratégico. A partir da análise de dados emergiram cinco categorias: esforço e comprometimento; lealdade à empresa; disposição para assumir riscos; capacidade de tomar decisões; e capacidade de negociação. A maioria dos entrevistados acredita que as mulheres são mais comprometidas e se esforçam mais; que são menos leais à empresa; que são menos centralizadoras e possuem menor poder de decisão; que são emocionalmente frágeis e passivas; e que precisam adotar uma postura mais agressiva para negociar. Estes dados indicam uma manutenção das representações sociais tradicionais de gênero, em que são atribuídas às mulheres traços de submissão, dependência, fragilidade, emotividade e responsabilidade pelas tarefas domésticas e cuidados relativos aos filhos. 
Palavras-chave: Representações Sociais. Relações de Gênero. Mulheres Executivas.

\begin{abstract}
The aim of this article is to investigate, from the perspective of male executives, the social representations about woman executives in regard to their actions in the work environment. The methodology uses a qualitative approach; in regard to the objectives, it is descriptive and the method adopted was a multiple case study. Three large Brazilian companies were analyzed. The sample consisted of 31 executives in positions of high strategic level. From the data analysis, five categories emerged: effort and commitment; loyalty to the company; willingness to take risks; ability to make decisions; and negotiation skills. Most of the respondents believe that women are more committed and strive harder; that they are less loyal to the company; that they are less centralized and have less decisionmaking power; that they are emotionally fragile and passive; and that they should adopt a more aggressive stance when negotiating. These data indicate a maintenance of the traditional social representations of gender, in which women are assigned characteristics of submission, dependence, fragility, emotionality and responsibility for domestic tasks and child care.
\end{abstract}

Keywords: Social Representations. Gender Relationships. Executive Women.

\title{
RESUMEN
}

El objetivo de este artículo fue investigar, desde la perspectiva de los hombres ejecutivos, las representaciones sociales en torno a la mujer ejecutiva, sobre su actuación en el ambiente de trabajo. La metodología tiene un enfoque cualitativo, en cuanto a los objetivos es descriptivo y el método adoptado fue el estudio de casos múltiples. Se analizaron tres grandes empresas de Brasil. La muestra fue compuesta por 31 ejecutivos con posiciones de alto nivel estratégico. A partir del análisis de datos surgieron cinco categorías: esfuerzo y compromiso; lealtad a la empresa; disposición para asumir riesgos; capacidad de tomar decisiones; y capacidad de negociación. La mayoría de los encuestados cree que las mujeres son más comprometidas y se esfuerzan más; que son menos leales a la empresa; que son menos centralizadoras y tienen menor poder de decisión; que son emocionalmente frágiles y pasivos; y que necesitan adoptar una postura más agresiva para negociar. Estos datos indican un mantenimiento de las representaciones sociales tradicionales de género, en las que se atribuyen a las mujeres rasgos de sumisión, dependencia, fragilidad, emotividad y responsabilidad por las tareas domésticas y cuidados relativos a los hijos.

Palabras clave: Representaciones Sociales. Relaciones de género. Mujeres Ejecutivas.

\section{INTRODUÇÃO}

0 estudo das representações sociais vem se expandindo no Brasil nos diferentes campos e áreas do conhecimento, revelando o seu caráter multidisciplinar (Arruda, 2000; 2002; Martins, Carvalho, \& Antunes-Rocha, 2014; Sá \& Arruda, 2000). A versatilidade do conceito (Allandottir, Jovchelovltch \& Stathopoulou, 1993) e de escolhas metodológicas permitem o estudo das representações acerca de diversos fenômenos sociais contemporâneos, entre eles o de gênero (Arruda, 2002; Jodelet, 2008).

$\mathrm{Na}$ área da Administração, a Teoria das Representações Sociais tem sido adotada para o estudo de diversos fenômenos organizacionais, inclusive relações de gênero dentro dos espaços organizacionais (Cappelle et al., 2002). É importante ressaltar que, embora o conceito de gênero seja muito mais amplo, este artigo foca em duas categorias opostas: masculino ou feminino (D'Amorim, 1997).

Uma busca realizada pelos autores no portal de periódicos SPELL (Scientific Periodicals Eletronic Library) revelou 85 artigos que abordaram a Teoria das Representações Sociais, mas apenas 10 destes artigos abordaram Representações Sociais e Gênero. Dos artigos que abordam Representações Sociais e Gênero, três buscaram identificar as representações sociais das mulheres sobre o que significa ser mulher no mundo dos negócios (Cramer et al., 2012), sobre o corpo feminino e as definições do feio e do belo (Cheung et al., 2014) e sobre 0 significado da ciência (Yamamoto \& Ichikawa, 2007). Outros três buscaram compreender as representações sociais de homens e mulheres sobre relações de gênero (Cappelle et al., 2002; Cramer et al., 2002; Vilas Boas et 
al., 2002). Dois buscaram analisar como homens gays representam a si próprios e os outros homossexuais (Eccel et al., 2015) e as representações sociais de secretários executivos gays em seus espaços de trabalho (Souza et al., 2015). Por fim, os dois últimos artigos buscaram analisar mídias de comunicação social para compreender as representações sociais de gênero nas organizações (Corrêa et al., 2007) e as representações femininas em revistas populares no mundo dos negócios (Melo et al., 2004).

Um estudo bibliométrico realizado por Martins-Silva et al. (2016) encontrou resultado semelhante. Os autores investigaram a produção científica de artigos que abordaram a Teoria das Representações Sociais no campo dos estudos organizacionais em eventos promovidos pela ANPAD e em periódicos brasileiros dos estratos A2 e B1. No período investigado, que compreendeu os anos de 2001 a 2014, foram identificados 90 artigos. Dentre os fenômenos sociais representados, apenas $10 \%$ dessa produção abordou relações de gênero e mulher. Portanto, no Brasil, pesquisas na área da Administração sobre Teoria das Representações Sociais e gênero são ainda mais raras, o que demonstra a relevância deste estudo.

Evidentemente, os estudos com enfoque de gênero dentro das organizações ampliaram com a participação da força feminina no mercado de trabalho brasileiro (Capelle et al., 2002). Logo, trata-se de um fenômeno organizacional relevante que justifica maior aprofundamento (Cappelle et al., 2007; Ferreira et al., 2015; Souza, Corvino, \& Lopes, 2013). No caso das mulheres executivas que estão no alto escalão, objeto deste estudo, as pesquisas são ainda mais restritas na área da administração (Carvalho Neto, Tanure, \& Andrade, 2010).

Atualmente, existem várias perspectivas teóricas que buscam investigar a questão do gênero nas profissões (Santos \& Amâncio, 2014). Dentre elas, situa-se a perspectiva de Acker (1990), que questiona a "neutralidade" de gênero dentro das organizações. Acker (1990) afirma que, embora existam variações nos padrões e extensão, as relações no local de trabalho são permeadas por imagens e crenças sobre masculinidade e feminilidade que reproduzem as desigualdades de gênero vigentes na sociedade. Essa perspectiva, portanto, se relaciona com o campo das representações sociais, na medida em que envolve as crenças, imagens, ideias e valores que permeiam as relações.

As representações estão vinculadas ao contexto de sua produção e, como qualquer fenômeno social, representam uma expressão da ação de sujeitos sociais que sentem, pensam, falam, se engajam e, consequentemente, transformam os contextos em que se encontram inseridos (Jovchelovitch, 1996). Do mesmo modo, as representações de gênero são construções sociais que sofrem modificações de acordo com o contexto histórico e cultural de uma determinada sociedade (Andrade, 2012). Assim, poderíamos nos perguntar se a ascensão de mulheres a posições hierarquicamente iguais aos homens nas organizações não implicaria mudanças nas representações historicamente construídas sobre o feminino.

A fim de ampliar o conhecimento e discussão sobre o tema este trabalho teve como objetivo identificar, a partir da perspectiva dos homens executivos, as representações sociais sobre a mulher executiva quanto à sua atuação no ambiente de trabalho.

Para tanto, 0 artigo foi estruturado em cinco partes. A primeira aborda os principais postulados da Teoria das Representações Sociais. A segunda estabelece uma relação entre representações sociais e relações de gênero nas organizações. A terceira apresenta informações sobre os aspectos metodológicos da pesquisa. $A$ quarta parte trata da análise dos dados. E, por fim, a quinta é destinada às considerações finais.

\section{FUNDAMENTAÇÃO TEÓRICA}

Nesta sessão, será apresentada a Teoria das Representações Sociais, desenvolvida em 1961 por Serge Moscovici. Posteriormente, serão estabelecidas aproximações entre a Teoria das Representações Sociais e as investigações sobre gênero nas organizações, especificamente de acordo com a perspectiva adotada por Acker (1990).

\subsection{Representações Sociais}

A Teoria das Representações Sociais é tanto uma maneira de ver os fenômenos sociais quanto um sistema que os descreve e explica (Moscovici, 1988). Desenvolvida por Moscovici em 1961, a teoria teve a sua origem no estudo intitulado La psychanalyse: son image et son public, que buscou analisar a difusão das ideias psicanalíticas na França (Duveen, 2013; Farr; 1987; 2013; Voelklein \& Howarth, 2005). 
O conceito foi originalmente introduzido no âmbito da psicologia social (Allandottir, Jovchelovltch \& Stathopoulou, 1993; Jodelet, 2008; Moscovici, 1988) e posteriormente foi adotado por outros campos do conhecimento (Höijer, 2011; Moscovici, 1988), em particular pela sociologia, linguística, antropologia, psicanálise e filosofia (Jodelet, 2008). Essa difusão é marcada por seu crescente uso e referência na Europa, América do Norte, América Latina e Ásia (Jodelet, 2008; Howarth, 2006). No Brasil, estudos realizados por Martins-Silva et al. (2016) e Mota et al. (2010) evidenciam o crescente uso da Teoria das Representações Sociais na Administração para estudos de fenômenos organizacionais cada vez mais complexos e diversificados.

As representações são um conjunto socialmente elaborado e partilhado de conhecimentos, valores, crenças, opiniões e atitudes específicas de um grupo (Abric, 2001; Jodelet, 2007). Uma vez que as representações se formam, elas moldam as formas cotidianas de fazer as coisas e o cenário social no qual nos relacionamos (Moscovici, 1988). Atribuímos sentido à realidade e nos relacionamos com o mundo e com os outros através das nossas representações sociais (Jodelet, 2001; Jovchelovitch, 1996a).

Definida como "saberes" cotidianos que circulam na sociedade (Jovchelovitch, 1996a), as representações moldam a consciência social de um período, uma classe ou uma nação. (Moscovici, 1988). Afinal, não somos indivíduos isolados, mas atores sociais afetados por diferentes aspectos da vida cotidiana (Jodelet, 2009).

As sociedades sempre impuseram palavras, ideias e imagens a nossos pensamentos e percepções. Nesse sentido, as representações são predeterminadas por convenções sociais. Mas, ao mesmo tempo, são repensadas e recriadas por sujeitos sociais (Moscovici, 2013), visto que o social também é subjetivo (Jovchelovitch, 1996b). Em síntese, "as pessoas são produtores e usuários de representações, tudo em um" (Moscovici, 1988, p. 233).

Como uma forma de estabelecer distinção entre esta forma de conhecimento e o conhecimento científico, as representações sociais também são conhecidas como "saber do senso comum" (Jodelet, 2008; 2001; Jovchelovitch, 2011). Nesse sentido, representações sociais são o conceito através do qual pesquisadores mapeiam o fenômeno do senso comum (Bauer \& Gaskell, 2008), um objeto de estudo tão legítimo quanto 0 conhecimento científico por sua importância na vida social (Jodelet, 2001).

0 conceito de representações sociais surgiu a partir da noção de representações coletivas de Durkheim (Bauer \& Gaskell, 2008; Moscovici, 1988; 2013; Voelklein \& Howarth, 2005). Porém, ao propor uma transição de coletivo para social, o autor procurou superar a perspectiva durkheimiana que alinha as representações individuais e coletivas como duas categorias dicotômicas opostas (Allandottir, Jovchelovltch \& Stathopoulou, 1993; Duveen, 2013; Jodelet, 2009; Moscovici, 1988).

A justificativa mais importante para a mudança terminológica, entretanto, veio da necessidade de enfatizar a qualidade dinâmica das representações sociais em oposição ao caráter estático das representações coletivas (Moscovici, 1988; 2013). Afinal, os fenômenos representacionais nas sociedades contemporâneas se caracterizam pela intensidade e fluidez das trocas e comunicações (Jodelet, 2001; Moscovici, 1988). Nesse contexto, o propósito das investigações das representações sociais é justamente entender uma vida social em um contexto de interrelações e ações que está sempre em formação (Moscovici, 1988).

Portanto, o fenômeno das representações sociais articula estruturas sociais e processos psicológicos (Jodelet, 2008) e busca investigar o pensamento social em sua dinâmica e em sua diversidade (Arruda, 2000). Afinal, o sujeito não está abstraído da realidade social nem condenado a ela (Jovchelovitch, 1996b). Novas representações estão constantemente surgindo para motivar a ação e dar sentido a uma realidade social em formação.

A versatilidade do conceito (Allandottir, Jovchelovltch \& Stathopoulou, 1993) e de escolhas metodológicas permitem o estudo das representações acerca de diversos fenômenos sociais contemporâneos, entre eles 0 de gênero (Arruda, 2002; Jodelet, 2008). O próprio Moscovici (1972) teceu uma análise das práticas e saberes cotidianos que separam o feminino e o masculino e que estabelecem uma relação social assimétrica, impedindo que a mulher alcance uma posição de igualdade com os homens.

\subsection{Representações Sociais e Relações de Gênero nas Organizações}

O termo "gênero" surgiu inicialmente entre as feministas americanas para enfatizar a construção social das diferenças baseadas no sexo em contraposição ao determinismo biológico vigente. Trata-se, portanto, de um 
termo utilizado para se referir às origens exclusivamente sociais dos papéis atribuídos aos homens e às mulheres (Kergoat, 2009; Nicholson, Soares \& Costa, 2000; Scott, 1986).

Por conseguinte, o conceito surge para diferenciar homens e mulheres social e culturalmente, expressando então o que cada sociedade entende como masculino e feminino (Scott, 1986). Johnson (1991) ressalta, por exemplo, que ao manter contato com outras culturas podemos muitas vezes questionar o que é ser feminino e o que é ser masculino. Nascer homem ou mulher, seja em qual sociedade for, passa por uma infinidade de influências sociais, que atribui significados, símbolos e representações específicas para interpretar cada um dos sexos. Assim, cria-se uma expectativa em relação aos comportamentos femininos e masculinos por conta da forma como as pessoas percebem os gêneros.

Nesse contexto, o trabalho assume uma representação de grande relevância, visto que é tido como uma das principais referências para a construção do modelo masculino de comportamento. Assim, desde muito cedo, os meninos têm o trabalho como representação de masculinidade. Ter uma agenda cheia de compromissos e preocupações laborais dão sentido à existência do homem de classe-média, e garante-lhe certo bem-estar psíquico. Em contrapartida, a não realização desses apelos gera profundo sentimento de mal-estar e fracasso (Nolasco, 1993).

A mulher, por outro lado, foi retratada historicamente como mãe, esposa dedicada e "rainha do lar". Assim, os limites das representações do feminino se atêm ao espaço maternal e doméstico. Aos homens, foi destinado 0 espaço público; às mulheres, o privado (Colling, 2004). No começo dos anos 70 , sob impulso do movimento feminista, uma onda de manifestações começou a questionar o que se denominou divisão sexual do trabalho (Kergoat, 2009). Fruto deste movimento, temos presenciado o aumento gradual da participação da mulher no mercado de trabalho (Tanure, 2006).

Embora ainda predomine a desigualdade de gênero em várias nações, tem sido significativo 0 crescimento da participação feminina na força de trabalho (Carli \& Eagly, 2016; Cuberes \& Teignier, 2016; Fortin, 2015; Gibb et al., 2014; Henderson, Ferreira, \& Dutra, 2016; Lucifora \& Vigani, 2016; Verick, 2014). As mulheres estão conquistando cada vez mais espaço em todo o mundo e em praticamente todas as atividades (Cappelle et al., 2007). No Brasil esse crescimento ocorre desde a década de 1970 (Andrade, 2012; Bruschini, 1994; 2007; Bruschini \& Puppin, 2004; Bruschini \& Lombardi, 2016; Gonçalves et al., 2016; Rocha et al., 2014).

Este contexto tornou possivel 0 aumento dos estudos organizacionais acerca das relações de gênero no ambiente de trabalho. Atualmente, existem várias perspectivas teóricas que buscam investigar a questão do gênero nas profissões (Santos \& Amâncio, 2014). Dentre elas, situa-se a perspectiva de Acker (1990) que questiona a "neutralidade" de gênero dentro das organizações.

Acker (1990) afirma que, embora existam variações nos padrões e extensão, as relações no local de trabalho são permeadas por imagens e crenças sobre masculinidade e feminilidade que reproduzem as desigualdades de gênero vigentes na sociedade. Essa perspectiva, portanto, se relaciona com o campo das representações sociais, na medida em que busca compreender a natureza simbólica do fenômeno, através das crenças, imagens, ideias e valores que permeiam as relações de gênero.

Uma pesquisa realizada por Betiol e Tonelli (1991) encontrou evidências de que as mulheres executivas, embora tenham galgado considerável ascensão no ambiente de trabalho, continuam a ser representadas pelo papel de mãe e esposa, visto que possuem respaldo social para fracassar na organização e voltar ao lar. Segundo as autoras, essa representação cria um clima contraditório de abertura e desconfiança da disponibilidade de investimento efetivo da mulher no trabalho, impactando as suas possibilidades de ascensão profissional. Aliás, essa representação de que a vida profissional da mulher concorre com a vida privada foi evidência de outras pesquisas (Andrade et al., 2002; Capelle et al., 2002; Cramer, Neto, \& Silva, 2002).

Andrade et al. (2002) encontrou representações de que mulheres possuem menos poder de decisão, cabendo aos homens assumir este papel. Os autores sugerem que essa representação limita o espaço da mulher a cargos e funções que envolvem menor poder ou participação no processo decisório. Assim, a carreira feminina passa a ter uma trajetória diferente da carreira masculina, especialmente no que tange às oportunidades de crescimento e remuneração.

A representação de que as mulheres são excessivamente cautelosas, encontrada na pesquisa realizada por Betiol e Tonelli (1991), também pode ter implicações para a ascensão profissional na mulher. Afinal, a cautela em excesso pode inibir a disposição para assumir riscos e, consequentemente, prejudicar a habilidade de tomar decisões. 
Outra evidência muito marcante em diversas pesquisas (Andrade et al., 2002; Betiol \& Tonelli, 1991; Capelle et al., 2002; Cramer, Neto, \& Silva, 2002) é a representação de que o ambiente organizacional é marcado por preconceito e ceticismo em relação à competência da mulher, assim ela tem que investir muito mais esforço para obter o mesmo reconhecimento que os homens.

Assim, os estudos sistematicamente têm evidenciado que a diferenciação entre as imagens masculinas e femininas geram representações de gênero no ambiente de trabalho que assumem caráter assimétrico (Amâncio, 1992), corroborando a teoria de Acker (1990). Enquanto as representações masculinas tornam os homens aptos para o trabalho, as representações femininas produzem sérias restrições ao trabalho da mulher nas organizações.

É o que Bourdieu (1999) caracteriza como dominação masculina, que se caracteriza pela presença invisível do pensamento ocidental, destacando a masculinidade como status de superioridade; é o machismo arraigado culturalmente. Carvalho Neto et al. (2014) apontam que as mulheres, muitas vezes, têm que se comportar como homens para se manterem no trabalho e alcançarem cargos mais altos.

Considerando, porém, que todos os fenômenos representacionais são dinâmicos e estão sempre em formação (Jodelet, 2001; Moscovici, 1988), as representações de gênero também são construções sociais que sofrem modificações de acordo com o contexto histórico e cultural de uma determinada sociedade (Andrade, 2012). Assim, uma pergunta que se impõe é se a ascensão de mulheres a posições hierarquicamente iguais aos homens nas organizações não implicaria mudanças nas representações historicamente construídas sobre 0 feminino.

Afinal, é preciso levar em conta a influência da crescente participação feminina na força de trabalho e a conquista de cargos com posições hierárquicas iguais aos homens na construção de novas representações sociais da mulher no mercado de trabalho (Andrade, 2012). Diante desse contexto, surgiu o interesse em investigar, a partir da perspectiva dos homens executivos, quais são as representações sociais em torno da mulher executiva, especificamente sobre a atuação no ambiente de trabalho.

\section{PROCEDIMENTOS METODOLÓGICOS}

Esta pesquisa teve como objetivo identificar, a partir da perspectiva dos homens executivos, as representações sociais sobre a mulher executiva quanto à sua atuação no ambiente de trabalho. $O$ objetivo primordial é a descrição das características de um fenômeno, tratando-se, portanto, de uma pesquisa descritiva. A abordagem qualitativa foi adotada por ser mais indicada quando o estudo é de caráter descritivo e busca 0 entendimento do fenômeno na sua complexidade (Godoy, 1995).

O método adotado foi o estudo de caso, indicado para a investigação empírica de um fenômeno em profundidade no seu contexto real (Yin, 2015). Especificamente, foi utilizado o estudo de casos múltiplos, sendo analisadas três empresas de grande porte do Brasil, duas do setor minerador e uma do setor automobilístico. A escolha das empresas se baseou na existência de mulheres executivas no seu quadro de funcionários e na disponibilidade em participar da pesquisa.

A amostra foi composta por 31 executivos, com idade média de 44 anos. Todos ocupam posições de alto nível estratégico. Dentre eles: 01 CEO, 03 diretores, 09 gerentes e 02 superintendentes representam as empresas mineradoras; e 02 diretores e 14 gerentes representam a empresa automobilística. A Tabela 1 ilustra a composição da amostra.

Tabela 1

Composição da Amostra

\begin{tabular}{|c|c|c|c|}
\hline Cargo & $\begin{array}{c}\text { Total empresa } \\
\text { Mineradoras }\end{array}$ & $\begin{array}{c}\text { Total empresa } \\
\text { Automobilística }\end{array}$ & $\begin{array}{c}\text { Total de executivos } \\
\text { entrevistados }\end{array}$ \\
\hline CEO & 01 & 0 & 01 \\
\hline Diretor & 03 & 02 & 05 \\
\hline Gerente & 09 & 14 & 23 \\
\hline Superintendente & 02 & 0 & 02 \\
\hline
\end{tabular}

Fonte: Composição própria (2018). 
Os dados foram coletados a partir de entrevistas semiestruturadas individuais e grupos focais, cujo roteiro foi previamente elaborado pelos autores (Apêndice A) com a ajuda da literatura. As perguntas do roteiro inicialmente passaram por uma avaliação de quatro pares: dois especialistas na temática de gênero e dois especialistas na teoria das representações sociais. O roteiro foi a campo para um teste piloto antes de ser utilizado com os entrevistados. A base teórico-empírica que sustentou a construção do roteiro surgiu do acúmulo de experiência de doze anos no campo nesta temática por parte de dois dos coautores deste artigo.

O CEO e os diretores foram entrevistados individualmente, com exceção de dois, que foram entrevistados em um grupo focal juntamente com 03 gerentes. Assim, foram realizadas 04 entrevistas individuais e 07 grupos focais, cada um composto por 04 participantes em média. Os pesquisadores se reuniram com cada grupo uma única vez, na própria empresa, durante 1 hora.

Os grupos focais são um tipo de entrevista flexível e não estruturada entre os membros de um grupo e um facilitador (Gaskell, 2003), cujo objetivo principal é estimular o debate aberto sobre um determinado tema (Boni \& Quaresma, 2005). Dada a produção coletiva e interativa das representações sociais, essa técnica é particularmente rica para este estudo (Jodelet, 2008). Portanto, a técnica de grupo focal foi escolhida por sua dinâmica permitir a comunicação e a interação dos participantes, favorecendo a emergência das representações sociais (Nóbrega, Andrade, \& Melo, 2016).

As entrevistas semiestruturadas individuais, por sua vez, foram escolhidas por permitirem um direcionamento maior para o tema proposto (Boni \& Quaresma, 2005). Desse modo, por meio dessa técnica, foi possível compreender com maior profundidade o fenômeno estudado. Todas as entrevistas individuais e em grupos focais foram gravadas e, posteriormente, transcritas na íntegra.

As dimensões de representações sociais analisadas nesta pesquisa emergiram da análise dos dados. Ao todo, foram identificadas cinco categorias: esforço e comprometimento; lealdade à empresa; disposição para assumir riscos; capacidade de tomar decisões; e capacidade de negociação.

A análise foi realizada sem ajuda de software. Para tanto, utilizou-se a análise de conteúdo, técnica que permite a categorização das entrevistas em categorias temáticas (Bardin, 2002). Foram consideradas todas as etapas sugeridas por Bardin (2002), quais sejam: pré-análise, exploração do material, tratamento dos resultados e interpretação dos dados. A fase de pré-análise compreendeu a seleção dos dados que foram submetidos à análise e à leitura flutuante de todo o material, processo por meio do qual foram obtidas as primeiras impressões do fenômeno em investigação. A segunda fase consistiu no processo de codificação, no qual dados brutos foram agregados em unidades temáticas. Cada unidade temática constituiu-se dos trechos selecionados das entrevistas transcritas, que foram agrupados em unidades comparáveis e com o mesmo conteúdo semântico. Posteriormente, foi realizado o processo de categorização, por meio do qual as unidades de registro foram agrupadas em categorias comuns, dando origem às cinco categorias de análise citadas. Por fim, na última etapa foi feita a interpretação dos dados.

\section{ANÁLISE DOS RESULTADOS}

Primeiramente, antes de iniciar a análise das categorias identificadas, torna-se fundamental contextualizar a atuação da mulher executiva no setor automobilístico. Trata-se de um setor que tradicionalmente emprega mão de obra predominantemente masculina (Araújo, 2001; Lapa, 2016; Neves, 2017). Nestes contextos, as mulheres costumam ser percebidas em termos de uma falta de adequação para exercer as suas funções, visto que os critérios de avaliação são baseados em estereótipos masculinos (Burgess \& Borgida, 1999). De acordo com Burgess e Borgida (1999), o uso destes critérios de estereótipo de gênero pode ter um impacto adverso sobre as mulheres nas decisões de contratação e promoção, já que são menos propensas a serem vistas de acordo com os atributos masculinos tidos como necessários ou desejáveis.

Em síntese, trata-se de um ambiente extremamente desafiador para as mulheres, uma vez que a suposta falta de atributos necessários para ter sucesso em profissões dominadas pelos homens torna propícia a existência de discriminação com base no sexo. É importante ressaltar que, nestes casos, geralmente não há intenção prejudicial para discriminar ou hostilidade para com as mulheres. Em vez disso, a discriminação ocorre como uma incompatibilidade entre os estereótipos de qualificação profissional masculinos e femininos (Burgess \& Borgida, 1999). 


\title{
4.1 Esforço e comprometimento
}

A maioria dos entrevistados acha que as mulheres são mais comprometidas e se esforçam mais para serem reconhecidas e atingir um crescimento profissional. Essa evidência já foi observada em outras pesquisas (Andrade et al., 2002; Betiol \& Tonelli, 1991; Capelle et al., 2002; Cramer, Neto, \& Silva, 2002). Uma das explicações para isso é que as mulheres precisam se esforçar mais no trabalho, porque o caminho dentro das organizações não está aberto, assim o investimento que elas têm que fazer é maior do que a maioria dos homens buscando o mesmo cargo (Betiol \& Tonelli, 1991). O relato a seguir ilustra a percepção coletiva:

A mulher é mais comprometida, faz de tudo para se manter onde chegou, é bem mais detalhista e preocupada com o trabalho. Há uma necessidade de estar tudo perfeito. (Entrevistado 14, Gerente)

A mulher tem que se forçar mais. Ela tem que provar mais e para isto tem que endurecer a força. (Entrevistado 26, Gerente)

Para os entrevistados, as mulheres executivas precisam provar sua competência o tempo inteiro por se deparar com muitas resistências provenientes do preconceito no ramo que atuam, predominantemente masculino. Na percepção deles, existe uma preocupação da mulher em "não falhar nunca e dar satisfação além do que se espera deles [homens executivos]" (Entrevistado 15, Diretor). A seguir, o relato de outro executivo também expressa essa percepção:

\begin{abstract}
A inserção da mulher é mais difícil, ela tem que andar um degrau a mais. A mulher tem que andar um degrau a mais que o homem. A gente tem um preconceito de que o carro é homem, que envolve mecânica, trabalho pesado, e você não associa a mulher a ele. 0 progresso da mulher é muito mais difícil nesse segmento. (Entrevistado 11, Gerente)
\end{abstract}

A análise dessa categoria sugere que as representações sociais da maioria dos executivos é de que as mulheres executivas precisam demonstrar maior esforço e comprometimento em uma tentativa de vencer o preconceito dentro das organizações. Ou seja, existe a representação social de que o reconhecimento e, consequentemente, a ascensão profissional da mulher executiva é mais difícil "tanto em relação a cargo quanto a salários" (Entrevistado 05, Gerente), corroborando a pesquisa realizada por Andrade et al. (2002).

\subsection{Lealdade à empresa}

Para a maioria dos executivos, a mulher é menos leal à empresa, visto que as demais tarefas, como cuidados com os filhos e com o lar, "divide sua atenção" (Entrevistado 23, CEO). Esta representação de que a vida profissional da mulher concorre com a vida privada já foi observada em outros estudos (Andrade et al., 2002; Betiol \& Tonelli, 1991; Capelle et al., 2002; Cramer, Neto, \& Silva, 2002).

Interessante observar que este mesmo executivo afirmou que a "mulher tem mais a perder, família, filhos, e isso a torna mais responsável [em relação à organização], sendo o homem mais inconsequente." (Entrevistado 23, CEO). A família é, então, ao mesmo tempo concebida como essencial para a motivação e como empecilho para a dedicação à carreira (Andrade et al., 2002). No entanto, a percepção coletiva é de que vida profissional da mulher concorre com a vida privada.

Entre alguns executivos houve a percepção da maior lealdade das mulheres à organização. Dois deles destacaram que a mulher seria mais leal à empresa por dar valor às conquistas que obteve ali, reforçando a representação social de maior dificuldade de ascensão profissional da mulher: "O homem pula mais, acha que alavanca a carreira mudando de lugar. A mulher acha que ficar na mesma empresa é melhor. Talvez trocar seja pior porque aí ela vai ter que provar tudo de novo" (Entrevistado 24, Gerente). "No entanto, o homem troca mais de emprego que a mulher. Para a mulher é mais difícil, ela teria que provar mais sua competência." (Entrevistado 19, Diretor). 
Um estudo realizado por Estivalete et al. (2009) sugere que as mulheres atribuem maior importância à independência financeira e à estabilidade profissional do que os homens, corroborando a percepção dos entrevistados. De acordo com esta pesquisa, as mulheres possuem, em média, tempo de empresa superior a dois anos em relação aos homens. De acordo com as autoras, esses resultados ilustram o papel das mulheres como provedoras ou participantes ativas na composição da renda familiar, como também indicam outras pesquisas (Fernandes et al., 2016; Moreira \& Silva, 2018; Silveira, 2006).

A análise dessa categoria sugere uma contradição importante: a maioria dos executivos considerou que a mulher é mais comprometida com o trabalho, mas também afirmou que ela é menos leal que o homem por ter uma atenção dividida com a familia. As representações sociais sugerem que as mulheres são menos leais à empresa, pois possuem maior responsabilidade pelos cuidados que envolvem a casa e os filhos. Assim, existe a representação de que a dedicação à família compete com o trabalho das mulheres executivas (Cramer, Neto, \& Silva, 2002).

\subsection{Disposição para assumir riscos}

Em relação à disposição para assumir riscos, as opiniões se dividiram. Alguns acreditam que os homens arriscam mais e outros acham que são as mulheres. 0 medo do homem em fracassar seria o principal fator que levaria as mulheres a arriscarem mais, de acordo com os entrevistados que acreditam que elas assumem mais riscos. Uma explicação para essa percepção pode ser que, na avaliação masculina, as mulheres não têm obrigação de ter sucesso profissional, assim o fracasso tem peso menor (Betiol \& Tonelli, 1991). Um executivo corrobora essa explicação ao afirmar que "a cultura do provedor pesa mais nele. Ela vai ter menos cobrança social." (Entrevistado 16, Diretor). É importante ressaltar que diversas pesquisas indicam que esta percepção social diverge do sentido que as próprias mulheres atribuem ao seu trabalho, uma vez que os seus resultados evidenciam que as mulheres estão muito comprometidas com a carreira e com a realização profissional (Estivalete et al., 2009; Fernandes et al., 2016; Moreira \& Silva, 2018; Silveira, 2006).

Por outro lado, os que acham que os homens arriscam mais atribuem o fato a uma questão cultural, em que a mulher delega ao homem maior poder de decisão (Andrade et al., 2002). É o que o relato a seguir ilustra: "Por causa da cultura, a mulher é mais acomodada, assume menos risco, se esconde mais atrás do chefe, como no caso do marido e da mulher, onde a mulher se esconde atrás do marido." (Entrevistado 03, Gerente).

Outros executivos apontaram que o maior autocontrole emocional dos homens permite que eles assumam mais riscos. Nas falas dos que avaliaram ser o homem quem arrisca mais, apareceram muitos fatores subjetivos e emocionais relacionados às mulheres. Elas, por serem mais emotivas e sentimentais, teriam mais dificuldade em arriscar, na avaliação deles.

A análise desta categoria sugere a representação social de que existe uma expectativa maior de sucesso (Betiol \& Tonelli, 1991), independência e poder de decisão centrada na figura masculina (D’Amorim, 1997). Além disso, sugere a representação feminina de dependência e submissão encontradas na literatura (Amâncio, 1992). Aqui claramente se evidencia o lugar secundário que a mulher ocupa na representação social dos homens executivos. Como afirma Beauvior (1980), a mulher é sempre vista como o "outro" e, consequentemente, é destinada a ocupar espaços secundários (Brescoll, 2016). Nessa perspectiva, cabe ao homem ocupar o espaço público, das decisões e, à mulher, o espaço doméstico, da submissão (Beauvior, 1980; Bourdieu, 1999).

\subsection{Capacidade de tomar decisões}

Assim como a baixa disposição para assumir riscos, a maior expressividade emocional das mulheres também foi citada como uma característica que prejudica a tomada de decisão. Alguns executivos alegaram que essa característica influencia na "imparcialidade" (Entrevistado 18, Diretor).

A crença de que as mulheres são mais emotivas do que os homens é um dos estereótipos de gênero mais fortes nas culturas ocidentais (Brescoll, 2016). Embora pesquisas sugiram que homens e mulheres são mais semelhantes do que diferentes a respeito de suas emoções (Heesacker et al., 1999), a literatura aponta que as mulheres costumam ser socialmente descritas como se tivessem menor autocontrole emocional ou como se fossem incapazes de separar os sentimentos de suas ideias (Brescoll, 2016; Else-Quest et al., 2006; Heesacker

Revista Alcance - Eletrônica - vol. 25 - n. 3 - Set./Dez. 2018 
et al., 1999). Por conseguinte, existe a crença de que as suas decisões seriam impulsionadas por suas emoções (Brescoll, 2016).

Essa representação de que homens possuem maior autocontrole emocional e que, consequentemente, são melhores tomadores de decisão, não é inócua e pode ser fundamental na explicação sobre o motivo de o espaço da mulher ser limitado a cargos e funções que envolvam menor participação no processo decisório. Assim, a mulher entra na empresa, mas não consegue ter a mesma trajetória de carreira masculina, principalmente no que se refere a oportunidades de crescimento e remuneração (Andrade et al., 2002; Brescoll, 2016; Cyrino, 2011).

Contudo, essa representação não foi unânime. Pode-se perceber nas entrevistas um movimento contrário a esse estereótipo, quando alguns executivos usaram esses mesmos argumentos para afirmar que o lado mais emocional da mulher a faz pensar e procurar mais evidências, decidindo de forma mais assertiva, como afirma um executivo: "as mulheres [...] têm mais chance de ser assertiva, porque ela pondera mais. 0 homem é mais impulsivo, impetuoso. É menos ponderado." (Entrevistado 24, Gerente)

Aqui, as mulheres continuam a ser percebidas como mais emotivas, porém, dessa vez, essa característica é vista como positiva. Ao mesmo tempo em que este estereótipo é descrito como negativo, uma vez que interfere no autocontrole, também é descrito como positivo pelo mesmo motivo, o que revela uma contradição. Como observou Heesacker et al. (1999), o estereótipo de gênero em relação à emoção é uma faca de dois gumes.

Devido a esta representação social de que cabe ao homem maior poder de decisão por causa do suposto menor autocontrole da mulher, grande parte dos executivos vai além, afirmando que os homens são mais centralizadores: "O homem é mais centralizador nas decisões, mas a mulher compartilha antes e depois, não só depois. Ele é mais centralizador." (Entrevistado 16, Diretor).

No momento em que ocorreu a fala anterior, os pesquisadores puderam observar que os homens, ao mesmo tempo em que se diziam mais centralizadores, se referiam de forma elogiosa às mulheres quanto à capacidade de elas compartilharem antes de tomar decisões. Talvez a representação de que os homens sejam melhores tomadores de decisões conduza à centralização do processo decisório.

\subsection{Capacidade de negociação}

$\mathrm{Na}$ forma de negociação todos os entrevistados consideraram a existência de diferenças entre homens e mulheres. A maioria dos executivos atribuiu características de brutalidade aos homens e amabilidade às mulheres. Mesmo aqueles que disseram que as mulheres são tão agressivas para negociar quanto os homens, fizeram questão de destacar que a forma e a abordagem são diferentes.

Os executivos associaram imediatamente a forma de negociação da mulher executiva com a expressão de sentimentos. Nesse momento, apontaram a maior expressividade emocional das mulheres como uma característica negativa por dois motivos: primeiro, por fragilizar a mulher diante de situações difíceis; e, segundo, por criar uma situação desigual que as favorece. Em relação a este segundo motivo, os executivos enxergam que a expressão dos sentimentos pode fazer com que o homem seja mais gentil em um momento de negociação, criando, assim, uma vantagem para as mulheres.

De acordo com um dos diretores, as mulheres negociam melhor com homens, pois, devido ao fato de expressarem mais os seus sentimentos, "com outra mulher a negociação não anda" (Entrevistado 18, Diretor). Em tom de crítica, o mesmo executivo afirma: "Elas são mais transparentes. Na minha sala quando recebo duas, três mulheres, é incrivel. Uma começa a falar e a outra já fecha a cara, elas expressam mesmo sem querer. 0 homem é mais controlado." (Entrevistado 18, Diretor).

Eles também afirmam que as mulheres não se impõem nas negociações, porque não valorizam o próprio trabalho e não questionam ordens, além de enfatizarem dificuldades relacionadas às características emocionais da mulher, como indica o relato a seguir: "Os homens entram na minha sala e me questionam quando ficam chateados com alguma decisão. As mulheres nunca fazem isso." (Entrevistado 16, Diretor). Outro entrevistado demonstra a mesma percepção:

O homem negocia melhor, a mulher tende a ser menos incisiva, este é o motivo maior por que o homem ganha mais dinheiro. Ao ter que negociar bônus, salários, ela desvaloriza seu próprio trabalho, ela reluta em colocar um valor como patamar, ela não quer provocar. Elas podem ser 
duras ao negociar para os outros, mas para ela não é igual, não impõem seu valor. (Entrevistado 28, Diretor)

Enquanto alguns executivos teceram reflexões acerca da "fragilidade" feminina, outros abordaram, em tom de crítica, a questão da "masculinização" do comportamento feminino, já abordada em diversos estudos (Carvalho Neto et al., 2014; Cyrino, 2011; Henderson et al., 2016, Lima et al., 2009; Tanure et al., 2006). De modo contraditório, um executivo afirmou que as "mulheres têm que ser mais agressivas para conseguir algo" (Entrevistado 05, Gerente) nas relações de negócio, mas também são criticadas quando demonstram agressividade para tentarem se impor em um ambiente fortemente dominado por valores "masculinos". Assim, um executivo acredita que "a mulher tem que tomar cuidado para não ser masculina ao extremo" (Entrevistado 13, Gerente). Em outro relato, um executivo afirma: "Percebe-se que das que atingiram o topo, há uma masculinização da mulher para chegar lá, ela perde uma série de caraterísticas femininas de liderança que são extremamente bem-vindas atualmente." (Entrevistado 06, Gerente)

Na contramão deste pensamento, um dos diretores afirma que essa "masculinização" é necessária, visto que o ramo em que essas mulheres estão atuando é dominado pelos homens. Desta forma, elas precisariam "assimilar o modelo de gestão masculino e não ser sensivel como prevê o estereótipo. Elas têm que ser masculinas, incisivas e agressivas". (Entrevistado 28, Diretor)

A análise das representações sociais sobre a capacidade de negociação revela que a mulher executiva é vista como emocionalmente frágil e que, em alguns momentos, utiliza essa característica em benefício próprio. Além disso, são vistas como passivas, por não se imporem e não questionarem regras.

As representações sociais, porém, são contraditórias, pois existe a crença de que a mulher precisa adotar uma postura mais agressiva para negociar, porém, quando adotam, são criticadas por serem muito "masculinas". Assim, a representação da mulher executiva envolve uma contradição entre a necessidade de trabalhar "como homem" e ao mesmo tempo ser "feminina". (Tanure et al., 2006)

\section{CONSIDERAÇÕES FINAIS}

A partir da perspectiva de Acker (1990) sobre a inexistência da "neutralidade" do gênero dentro das organizações, este artigo teve como objetivo identificar, a partir da perspectiva dos homens executivos, as representações sociais sobre a mulher executiva quanto à sua atuação no ambiente de trabalho. Para Acker (1990), embora existam variações nos padrões e na extensão, as relações no local de trabalho são permeadas por imagens e crenças sobre masculinidade e feminilidade que reproduzem as desigualdades de gênero vigentes na sociedade. Essa perspectiva, portanto, se relaciona com o campo das representações sociais, na medida em que envolve crenças, imagens, ideias e valores que permeiam as relações.

No seu conjunto, os relatos indicam que existe uma manutenção das representações sociais tradicionais de gênero, em que são atribuídas às mulheres traços de submissão, dependência, fragilidade, emotividade e responsabilidade pelas tarefas domésticas e cuidados relativos aos filhos. Aos homens, por sua vez, são atribuídos traços de ousadia, independência, poder de decisão e racionalidade. É como se o feminino e o masculino fossem duas categorias dicotômicas opostas e só existisse uma possibilidade de ser. Essas representações, já abordadas na literatura (Amâncio, 1989; 1992; 1993; 1996; Brescoll, 2016; Eagly, 1995; Eagly \& Kite, 1987), estabelecem assimetria entre os gêneros no ambiente de trabalho, pois justificam e legitimam as diferentes posições objetivas entre os dois sexos.

Os executivos entrevistados reconhecem que o ambiente organizacional é permeado por representações machistas sobre o feminino ao afirmarem que a ascensão profissional da mulher executiva é diferenciada, visto que elas precisam ser mais comprometidas e se esforçar para obterem o mesmo reconhecimento e crescimento profissional que os homens. Eles atribuem este fato às barreiras do preconceito que as mulheres enfrentam em um ambiente dominado por valores masculinos.

Os executivos também possuem a representação social de que a dedicação à família compete com o trabalho das mulheres executivas e que, por isso, elas são menos leais à empresa. Ou seja, a representação social dos homens executivos é que os cuidados que envolvem a casa e os filhos ainda são obrigações femininas, representações características de países com valores machistas e patriarcais como o Brasil, conforme indica a 
literatura (Carvalho Neto, Tanure, \& Andrade, 2010; Tanure, Carvalho Neto, \& Andrade, 2006; Narvaz, 2005; Narvaz \& Koller, 2006).

Eles também revelaram a representação social de que as mulheres executivas possuem baixa disposição para assumir riscos devido a traços de submissão e dependência culturalmente arraigados. Assim, eles acreditam que as mulheres preferem delegar ao homem maior poder de decisão. Por outro lado, existe a representação social de que a mulher arrisca mais, talvez porque o fracasso profissional feminino não tem a mesma relevância social do que o masculino, como supõem Betiol e Tonelli (1991).

Aliás, a representação de que as mulheres executivas não são boas tomadoras de decisão foi reforçada mais de uma vez, quando os executivos afirmam que a característica emocional atribuída às mulheres influencia a imparcialidade da decisão. Essa representação de que homens são melhores tomadores de decisão pode ser fundamental na explicação sobre o motivo de o espaço da mulher ser limitado a cargos e funções que envolvam menor participação no processo decisório, como presumem Andrade et al. (2002). Contudo, essa representação não foi unânime, pois há também a representação social de que a característica mais emocional da mulher a faz pensar e procurar mais evidências, decidindo de forma mais assertiva.

A análise das representações sociais sobre a capacidade de negociação revela que a mulher executiva é vista pelos homens executivos como emocionalmente frágil e que, em alguns momentos, utiliza essa característica em benefício próprio. Além disso, as mulheres são vistas como passivas, por não se imporem e não questionarem regras. Essas representações, porém, são contraditórias, pois existe a crença de que a mulher precisa adotar uma postura mais agressiva para negociar. Porém, quando a adotam, são criticadas por serem muito "masculinas". Assim, a representação da mulher executiva envolve uma contradição entre a necessidade de se comportar de acordo com os valores masculinos para ser reconhecida e, ao mesmo tempo, ser feminina.

As contradições percebidas ao longo das entrevistas são significativas para a compreensão do momento atual de questionamentos e transições paradigmáticas que não ocorrem sem conflitos, embates e hesitações. Como as relações de gênero estão em constantes transformações, percebe-se que algumas representações estão sofrendo alterações, uma vez que há cada vez mais mulheres dentro das organizações e em cargos de alto escalão. Acredita-se que, com o passar do tempo, representações que associam a mulher à submissão e como responsável pelas tarefas domésticas podem diminuir.

É possível dizer que este estudo traz contribuições e avança na literatura na medida em que relaciona representações sociais e gênero, tema ainda pouco explorado na Administração. No caso das mulheres executivas que estão no alto escalão, objeto deste estudo, as pesquisas são ainda mais restritas.

Este estudo, porém, apresenta limitações devido ao fato de o setor automobilístico e minerador ser predominantemente masculino. Assim, sugere-se que futuras pesquisas sejam realizadas em empresas de outros ramos, incluindo aquelas em que há a predominância de mulheres ocupando cargos executivos.

\section{REFERÊNCIAS}

Abric, J. C. (2001). L'approche structurale des représentations sociales: développements récents. Psychologie et société, 4(2), 81-104.

Acker, J. (1990). Hierarchies, jobs, bodies: A theory of gendered organizations. Gender \& society, 4(2), 139-158. http://www.jstor.org/stable/189609.

Allansdottir, A., Jovtchelovitch, S., \& Stathopoulou, A. (1993). Social Representations: the versatility of a concept. Papers on social representations, 2, 3-10.

Amâncio, L. (1989). Social differentiation between 'dominant'and 'dominated'groups: Toward an integration of social stereotypes and social identity. European Journal of Social Psychology, 19(1), 1-10.

Amâncio, L. (1992). Assimetrias nas representações de género. Revista Crítica de Ciências Sociais, (34), 9-22.

Amâncio, L. (1993). Representações e identidade. Sociologia - Problemas e Práticas, (14), 127-140.

Amâncio, L. (1996). Gender, expertise and authority. The effect of gender and specialized knowledge on the percepction of authority. Psicologia, (1), 11-25.

Andrade, S. R. D. (2012). Eu sou uma pessoa de tremendo sucesso: representações, identidades e trajetórias de mulheres executivas no Brasil. Tese de Doutorado, Fundação Getúlio Vargas, Rio de Janeiro, RJ, Brasil. 
Andrade, Á. L. S, Cappelle, M. C. A, Brito, M. J. de, Paula Neto, A. de \& Vilas Boas, L. H. de B. (2002). Gênero nas organizações: um estudo no setor bancário. RAE-eletrônica, 1(2).

Araújo, A. M. C. (2001). Gênero no trabalho. Cadernos Pagu, (17-18), 131-138.

Arruda, A. (2000). Feminismo, gênero e representações sociais. Textos de História. Revista do Programa de Pós-graduação em História da UnB, 8(1-2), 113-138.

Arruda, A. (2002). Teoria das representações sociais e teorias de gênero. Cadernos de Pesquisa, (117), $127-$ 147.

Bardin, L. (2002). Análise de Conteúdo. Lisboa, Portugal: Edições 70, LTDA.

Bauer, M. W., \& Gaskell, G. (2008). Social representations theory: A progressive research programme for social psychology. Journal for the theory of social behaviour, 38(4), 335-353.

Betiol, M. I. S., \& Tonelli, M. J. (1991). A mulher executiva e suas relações de trabalho. Revista de Administração de Empresas, 31(4), 17-33.

Beauvoir, S. D. (1980). O segundo sexo, v.1, 2. Tradução Sérgio Milliet. Rio de Janeiro: Nova Fronteira, 9.

Boni, V., \& Quaresma, S. J. (2005). Aprendendo a entrevistar: como fazer entrevistas em Ciências Sociais. Em Tese, 2(1), 68-80.

Bourdieu, P. (1999). A Dominação Masculina. Rio de Janeiro: Bertrand Brasil.

Burgess, D., \& Borgida, E. (1999). Who women are, who women should be: descriptive and prescriptive gender stereotyping in sex discrimination. Psychology, Public Policy, and Law, 5(3), 665.

Brescoll, V. L. (2016). Leading with their hearts? How gender stereotypes of emotion lead to biased evaluations of female leaders. The Leadership Quarterly, 27(3), 415-428.

Bruschini, C. (1994). O trabalho da mulher brasileira nas décadas recentes. Estudos feministas, Número Especial, pp. 179-199.

Bruschini, C. (2007). Trabalho e gênero no brasil nos últimos dez anos. Cadernos de Pesquisa, v. 37, n. 132, pp. $537-572$

Bruschini, C., \& Lombardi, M. R. (2016). O trabalho da mulher brasileira nos primeiros anos da década de noventa. Anais, 483-516.

Bruschini, C., \& Puppin, A. B. (2004). Trabalho de mulheres executivas no Brasil no final do século XX. Cadernos de pesquisa, 34(121), 105-138.

Cappelle, M. C. A., Silva, Á. L., Boas, L. H. D. B. V., \& de Brito, M. J. (2002). Representações das relações de gênero no espaço organizacional público. Revista de Administração Pública, 36(2), 253-275.

Cappelle, M. C. A., Brito, M. J., de, Melo, M. C. de O. L. M., \& Vasconcelos, K. A. (2007). A produção científica sobre gênero nas organizações: uma meta-análise. REAd-Revista Eletrônica de Administração, 13(3).

Carli, L.; Eagly, A. (2016) Women face a labyrinth: an examination of metaphors for women leaders. Gender in Management: An International Journal, 31(8), 514-527.

Carvalho Neto, A., Tanure, B., \& Andrade, J. (2010). Executivas: Carreira, Maternidade, Amores e Preconceitos. RAE-eletrônica, 9(1).

Carvalho Neto, A., Tanure, B., \& Santos, C. M. (2014). Pride and prejudice beyond the glass ceiling: Brazilian female executives' psychological type. Revista de Ciências da Administração, 16(39), 210-223.

Cheung, T. L., de Souza Alves, C., \& Sauer, L. (2014). Estatística Multivariada e Tipologia: consumindo serviços de estética. Revista Gestão \& Conexões, 3(2), 70-85.

Colling, A. (2004). A construção histórica do feminino e do masculino. Gênero e cultura: questões contemporâneas. Porto Alegre: EDIPUCRS, 2004.

Corrêa, A. M. H., Gontijo, M. C. L., Assis, L. B. D., Carrieri, A. D. P., \& Melo, M. C. D. O. L. (2007). Soldadinhosde-chumbo e bonecas: representações sociais do masculino e feminino em jornais de empresas. Revista de Administração Contemporânea, 11(2), 191-211. 
Cuberes, D., \& Teignier, M. (2016). Aggregate effects of gender gaps in the labor market: A quantitative estimate. Journal of Human Capital, 10(1), 1-32.

Cyrino, R. (2011). Essencialismo de gênero e identidade sexual: o caso das mulheres executivas. Caderno Espaço Feminino, 24(1).

Cramer, L., Cappelle, M. C. A., Andrade, Á. L. S., \& Brito, M. J. de (2012). Representações femininas da ação empreendedora: uma análise da trajetória das mulheres no mundo dos negócios. REGEPE - Revista de Empreendedorismo e Gestão de Pequenas Empresas, 1(1), 53-71.

Cramer, L., Neto, P., \& Silva, Á. L. (2002). A inserção do feminino no universo masculino: representações da educação superior. Organizações \& Sociedade, 9(24), 25-37.

D'Amorim, M. A. (1997). Estereótipos de gênero e atitudes acerca da sexualidade em estudos sobre jovens brasileiros. Temas em Psicologia, 5(3), 121-134.

Duveen, G. (2013). Introdução: o poder das ideias. In.: Moscovici, S. (2013). Representações Sociais: investigações em psicologia social (10a ed., pp. 07-28). Petrópolis, Rio de Janeiro: Vozes.

Eagly, A. H. (1995). The science and politics of comparing women and men. American Psychologist, 50(3), 145.

Eagly, A. H., \& Kite, M. E. (1987). Are stereotypes of nationalities applied to both women and men? Journal of Personality and Social Psychology, 53(3), 451.

Eccel, C. S., Saraiva, L. A. S., \& de Pádua Carrieri, A. (2015). Masculinidade, autoimagem e preconceito em representações sociais de homossexuais. Revista Pensamento Contemporâneo em Administração, 9(1), 01-15.

Else-Quest, N. M., Hyde, J. S., Goldsmith, H. H., \& Van Hulle, C. A. (2006). Gender differences in temperament: a meta-analysis. Psychological bulletin, 132(1), 33.

Estivalete, V. D. F. B., Löbler, M. L., de Andrade, T., \& Visentini, M. S. (2011). As implicações de gênero na hierarquia dos valores relativos ao trabalho. Revista Alcance, 18, 271-286.

Farr, R. (1987). Social Representations: A French Tradition of Research. Journal for the theory of social behaviour, 17(4), 343-365.

Farr, R. (2013). Representações sociais: a teoria e sua história. In: Guareschi, P., \& Jovchelovitch, S. (Orgs.). Textos em representações sociais (14a ed., pp. 27 -51). Petrópolis, Rio de Janeiro: Vozes.

Fernandes, T. D. S., Lopes, G. S. C., Watanabe, M., Yamaguchi, C. K., \& Godoi, C. K. (2016). Dimensões do empoderamento feminino: autonomia ou dependência? Revista Alcance (Online), 23(3), 391.

Ferreira, J. B, Sadoyama, S. P. A., Correia, A. F. C, \& Gomes, P. A T. de P. (2015). Diversidade e gênero no contexto organizacional: um estudo bibliométrico. Revista Pensamento Contemporâneo em Administração, 9(3).

Fortin, N. M. (2015). Gender role attitudes and women's labor market participation: Opting-out, aids, and the persistent appeal of housewifery. Annals of Economics and Statistics/Annales d'Économie et de Statistique, (117/118), 379-401.

Gaskell, G. (2003). Entrevistas individuais e grupais. In: Bauer, M. W., \& Gaskell, G. Pesquisa qualitativa com texto, imagem e som: um manual prático (pp. 64-89). Petrópolis: Vozes.

Gibb, S. J., Fergusson, D. M., Horwood, L. J., \& Boden, J. M. (2014). The effects of parenthood on workforce participation and income for men and women. Journal of Family and Economic Issues, 35(1), 14-26.

Godoy, A. S. (1995). Pesquisa qualitativa: tipos fundamentais. Revista de Administração de Empresas, 35(3), 2029.

Gonçalves, E. B. de P., Espejo, M. M. dos S. B., Altoé, S. M. L., \& Voese, S. B. (2016). Gestão da diversidade: um estudo de gênero e raça em grandes empresas brasileiras. Enfoque, 35(1), 95.

Harding, S., \& Pereira, V. (1993) A instabilidade das categorias analíticas na teoria feminista. Estudos Feministas, n.1, p. 7-31.

Heesacker, M., Wester, S. R., Vogel, D. L., Wentzel, J. T., Mejia-Millan, C. M., \& Goodholm Jr, C. R. (1999). Gender-based emotional stereotyping. Journal of Counseling Psychology, 46(4), 483. 
Henderson, P. A., de Araújo Ferreira, M. A., \& Dutra, J. S. (2016). As barreiras para a ascensão da mulher a posições hierárquicas: um estudo sob a óptica da gestão da diversidade no Brasil. Revista de Administração da Universidade Federal de Santa Maria, 9(3), 489-505.

Höijer, B. (2011). Social representations theory. Nordicom review, 32(2), 3-16.

Howarth, C. (2006). A social representation is not a quiet thing: Exploring the critical potential of social representations theory. British journal of social psychology, 45(1), 65-86.

Jodelet, D. (2001). As representações sociais. Rio de janeiro: Eduerj, 17-44.

Jodelet, D. (2007). Place de l'expérience vécue dans le processus de formation des représentations sociales. J.M. Tremblay.

Jodelet, D. (2008). Social representations: The beautiful invention. Journal for the Theory of Social Behaviour, 38(4), 411-430.

Jodelet, D. (2009). O movimento de retorno ao sujeito e a abordagem das representações sociais. Sociedade e estado, 24(3).

Johnson, R. (1991). Feminilidade perdida e reconquistada. São Paulo: Mercuryo.

Jovchelovitch, S. (1996a). In defence of representations. Journal for the theory of social behaviour, 26(2), 121135.

Jovchelovitch, S. (1996b). Espaços de mediação e gênese das representações sociais. Psico, 27(1), 193-205.

Jovchelovitch, S. (2011). Representações sociais e polifasia cognitiva: notas sobre a pluralidade e sabedoria da Razão em Psicanálise, sua imagem e seu público.

Kergoat, D. (2009). Divisão sexual do trabalho e relações sociais de sexo. Dicionário crítico do feminismo. São Paulo: Editora UNESP.

Lapa, T de Souza. (2016). Desigualdade salarial por sexo: persistências, transformações e desafios. Revista da ABET.

Lima, G. S., Lima, M. S., \& Tanure, B. (2009). Os Desafios da Carreira da Mulher Executiva no Brasil. Anais do Encontro de Gestão de Pessoas e Relações de Trabalho, Curitiba, PR, Brasil.

Lucifora, C.; Vigani, D. (2016). What If Your Boss Is a Woman? Work Organization, Work-Life Balance and Gender Discrimination at the Workplace, IZA Discussion Papers, No. 9737, Institute for the Study of Labor (IZA), Bonn.

Martins, A. M., Carvalho, C. A. da S., \& Antunes-Rocha, M. I. (2014). Pesquisa em representações sociais no Brasil: cartografia dos grupos registrados no CNPq. Psicologia: teoria e prática, 16(1), 104-114. Recuperado em 08 de junho de 2018, de http://pepsic.bvsalud.org/scielo.php?script=sci_arttext\&pid =S1516$36872014000100009 \&$ lng=pt\&tlng=pt.

Martins-Silva, P. de O., Silva Junior, A. da, Peroni, G. G H., Medeiros, C. P. de, \& Vitória, N. O. da. (2016). Teoria das representações sociais nos estudos organizacionais no Brasil: análise bibliométrica de 2001 a 2014. Cadernos EBAPE.BR, 14(4), 891-919.

Melo, M. C. D. O. L., Cappelle, M. C. A., Mageste, G. D. S., \& Brito, M. J. M. (2004). Representações femininas na mídia de negócios brasileira. Organizações \& Sociedade, 11(31), 103-118.

Moreira, M. G \& Silva, A. H. (2018). A influência do conflito trabalho-família e comprometimento com a carreira na percepção de sucesso na carreira de mulheres docentes. Revista Alcance, 25(2).

Morin, E. M. (2001). Os sentidos do trabalho. Revista de administração de empresas, 41(3), 08-19.

Moscovici, S. (1972). La Société contre Nature. Union générale d'édition, Paris, 1972, 404 p.

Moscovici, S. (1988). Notes towards a description of social representations. European journal of social psychology, 18(3), 211-250.

Moscovici, S. (2013). Representações Sociais: investigações em psicologia social (10a ed.). Petrópolis, Rio de Janeiro: Vozes. 
Mota, F. P. B., Beck, C, G., Pereira, R. de C. de F., Lima, T. A. P. de., Vale, S. C. (2010). A utilização de teorias em estudos organizacionais brasileiros: uma análise bibliométrica. Administração: Ensino e Pesquisa. Rio de Janeiro, v. 11, n. 3, p. 447-467.

Narvaz, M. (2005). Submissão e resistência: explodindo o discurso patriarcal da dominação feminina. Dissertação de Mestrado, Universidade Federal do Rio Grande do Sul, Rio Grande do Sul, Porto Alegre, Brasil.

Narvaz, M., \& Koller, S. H. (2006). Famílias e patriarcado: da prescrição normativa à subversão criativa. Psicologia \& Sociedade. São Paulo. v. 18, n. 1, 49-55.

Neves, T. D. C. (2017). Novas e velhas relações de trabalho na fábrica mais moderna do Brasil: o caso do polo automotivo Jeep em Goiana-PE (2015-2016) (Dissertação de Mestrado, Brasil).

Nicholson, L., Soares L. F. G., \& Costa, C. L. de. (2000). Interpretando o gênero. Estudos Feministas, 8(2), 9-41. Nolasco, S. A. (1993). O mito da masculinidade. Rio de Janeiro: Rocco.

Nóbrega, D. O., Andrade, E. D. R. G., \& Melo, E. S. D. N. (2016). Pesquisa com grupo focal: contribuições ao estudo das representações sociais. Psicologia \& Sociedade, 28(3), 433-441.

Sá, C. P., \& Arruda, A. (2000). O estudo das representações sociais no Brasil. Revista de ciências humanas, 19, 11-31. Florianópolis: EDUFSC, Edição Especial Temática.

Santos, M. H. \& Amâncio, L. (2014). Sobre minorias em profissões marcadas pelo género: consequências e reações. Análise Social, (212), 700-726. Recuperado em 08 de junho de 2018, de http://www.scielo.mec.pt/scielo.php?script=sci_arttext\&pid=S0003-25732014000300007\&lng=pt\&tlng=es

Silveira, N. S. da (2006). A diversidade de gênero e as diferenças e semelhanças na hierarquia de valores do trabalho de homens e mulheres no chão de fábrica. REGE - Revista de Gestão, 13(spe), 77-91.

Scott, J. (1986). Gender: A Useful Category of Historical Analysis. The American Historical Review, 91(5), 10531075.

Souza, E. M; Covino, M. de M. F., \& Lopes, B. C. (2013). Uma análise dos estudos sobre o feminino e as mulheres na área de administração: a produção científica brasileira entre 2000 a 2010. Organizações \& Sociedade, 20(67), 603-621.

Souza, E. C. P., Martins, C. B., \& de Souza, R. B. (2015). As representações sociais de secretários executivos gays: questões de gênero e diversidade no trabalho. Revista Gestão \& Conexões, 4(1), 116-139.

Tanure, B., Carvalho Neto, A., \& Andrade, J. O. (2006). A Super Executiva às voltas com Carreira, Relógio Biológico, Maternidade, Amores e Preconceitos. Anais do Encontro Nacional da Associação Nacional de PósGraduação e Pesquisa, Salvador, BA, Brasil.

Yamamoto, J. M. \& Ichikawa, E. Y. (2008). Representações sociais da ciência: o que dizem as mulheres pesquisadoras da Universidade Estadual de Maringá. Revista Alcance, 14, 27-48.

Yin, R. (2015). Introdução: quando usar os estudos de caso como método de pesquisa (5a ed., pp. 03-27). In.: Yin, R. Estudo de caso: Planejamento e Método. Porto Alegre: Bookman.

Verick, S. (2014). Female labor force participation in developing countries. IZA World of Labor.

Vilas Boas, L. H. D. B., de Paula Neto, A., \& Cramer, L. (2002). Relações de gênero nas organizações: um estudo no setor de vendas de veículos. Revista de Administração da Universidade de São Paulo, 38(3).

Voelklein, C. \& Howarth, C. (2005). A review of controversies about social representations theory: A British debate. Culture \& psychology, 11(4), 431-454. 
APÊNDICE A - Roteiro para entrevista individual e em grupo

1. Existem diferenças nas formas como homens e mulheres exercem as suas funções de gerência?

2. Na sua opinião, qual é a diferença mais marcante?

3. Existem diferenças nos desafios que homens e mulheres enfrentam ao exercer cargos de gerência?

4. Gerentes homens e mulheres possuem diferenças quanto às habilidades de negociação?

5. Gerentes homens e mulheres possuem diferentes quanto à disposição para assumir riscos? 